\title{
Inhibitory Effect of Coffee Extract against Some Mutagens
}

\author{
Tsutomu Yamaguchi and Makiyo IKI \\ Department of Living and Health, Joetsu University of Education, \\ Joetsu, Niigata 943, Japan
}

Received April 7, 1986

\begin{abstract}
The effects of coffee extracts on mutagenicity were studied using the Salmonella typhimurium system. Coffee extracts showed inhibitory effects on the mutagenicity of such mutagens as 3-amino1-methyl-5H-pyrido[4,3- $b$ ]indole (Trp-p-2), 2-acetylaminofluorene (AAF), and benzo(a)pyrene (B(a)P), whose mutagenicity require metabolic activation by rat liver microsomal fraction, S-9 mix. The inhibition of mutagenicity increased in proportion to the level of roasting or to the darkness in color of the coffee extracts. When the coffee extracts were applied to a Sephadex G-50 column, two color pigment peaks were observed, the second peak showing the inhibitory activity towards mutagenicity. The inhibitory substance towards the mutagenicity was formed only in a heat-treated mixture of sucrose with either chlorogenic or caffeic acid, among various heat-treated combinations of components in raw coffee beans. The decrease of mutagenicity by coffee extracts was due to inhibiting the metabolic activation by $\mathrm{S}-9 \mathrm{mix}$.
\end{abstract}

It has been reported that the pyrolysis of some foods produces such mutagens as 3-amino-1,4-dimethyl-5H-pyrido[4,3- $b]$ indole (Trp-p-1), Trp-p-2, 2-amino-6-methyldipyrido[1,2-a:3', $\left.2^{\prime}-d\right]$ imidazole (Glu-p-1) and 2-aminodipyrido[1,2-a:3',2'-d]imidazole (Glu-p-2). ${ }^{1,2)}$ On the other hand, some foods contain such anti- or desmutagens as peroxidase, ${ }^{3)}$ long chain fatty acids, ${ }^{4)}$ biologically active quinones, ${ }^{5)}$ hemin ${ }^{6)}$ and rethinoids. ${ }^{7)}$

Nagao et $a l .{ }^{8)}$ have reported that coffee extracts, prepared by lyophilizing what was extracted from ground coffee in the usual way for drinking and then dissolving the lyophilized powder in dimethyl sulfoxide, showed mutagenicity on Salmonella typhimurium TA 100 without S-9 mix. The mutagenic substance was identified as methylglyoxal, which was formed during the process of roasting the raw coffee beans. ${ }^{9)}$

We found in this study that the coffee extracts had inhibitory effects on the mutagenicity of such mutagens as Trp-p-2, AAF and B(a)P. Our coffee extracts were prepared in the usual way for drinking, but were not lyophilized nor dissolved in dimethyl sulf- oxide as Nagao et al. did. ${ }^{8)}$ Whereas the mutagenicity assay method by Nagao et al. ${ }^{8)}$ was to mix a tester strain with coffee extracts before determining the revertants formed, our system was to mix a tester strain with a mutagen before determining the effects of coffee extracts on the revertants formed by the mutagen. Methylglyoxal was confirmed to have no inhibitory effect on the mutagenicity of these mutagens, so it seemed necessary to study the inhibitory substance in coffee extracts in detail.

It was found that the inhibitory substance was in some color pigments which were formed during the roasting process of raw coffee beans.

\section{MATERIALS AND METHODS}

Microorganisms. The histidine-requiring strains of Salmonella typhimurium TA 98 and TA 100 were kindly supplied by Dr. B. N. Ames.

Materials. Sucrose, glycine and caffeine were purchased from Wako Chemicals Co. Chlorogenic acid and caffeic acid were from Nakarai Chemicals Co. All other reagents used were of guaranteed grade. 
Coffee beans of three differing levels of roasting, American (low), medium, and Italian (high), were obtained from a coffee shop. Coffee extracts were prepared by finely grinding the beans in a home coffee mill, before filtering $20 \mathrm{~g}$ of ground coffee and $200 \mathrm{ml}$ of boiling water through filter paper (Melitta, No. 0-1000-16, Pa $1 \times 4 \mathrm{G}$, West Germany). Usually, $160 \mathrm{ml}$ of filtrate was obtained.

The liver microsomal fraction (S-9 mix) was prepared polychloro biphenyl (PCB) as described by Ames et al. ${ }^{11)}$

Assay of inhibitory activity. An inhibitory activity assay on the mutagenicity was carried out according to Ames et al. with some modifications. ${ }^{12)}$ A mixture of $0.1 \mathrm{ml}$ of cells of the test strain, $0.05 \mathrm{ml}$ of coffee extract $(1 \%$ in hot water), $0.25 \mathrm{ml}$ of S-9 mix or $0.1 \mathrm{M}$ phosphate buffer $(\mathrm{pH}$ 7.2 ), and $0.1 \mathrm{ml}$ of the mutagen solution was incubated at $37^{\circ} \mathrm{C}$ for $90 \mathrm{~min}$, before being poured onto an ager layer. After incubating at $37^{\circ} \mathrm{C}$ for $48 \mathrm{hr}$, the $\mathrm{His}^{+}$revertant colonies were counted.

Assay of color intensity. The brown color intensity of the sample was determined by measuring the absorbance at $400 \mathrm{~nm}$ with a Hitachi Model 200-20 spectrophotometer.

Fractionation of brown pigments in coffee extracts. The coffee extracts $(15 \%, 1.0 \mathrm{ml})$ were applied to a Sephadex G-50 column $(1.0 \times 25 \mathrm{~cm})$, which had been equilibrated beforehand with $0.1 \% \mathrm{NaCl}$ solution. The column was washed and eluted the same solution. The flow rate was $0.5 \mathrm{ml} / \mathrm{min}$, and $3.0 \mathrm{ml}$ were collected for each fraction. The color intensity and inhibitory activity towards mutagenicity was measured for each fraction.

Model roasting test. In order to clarify which components in raw coffee beans produced these inhibitory substances, a model roasting test was carried out according to Nakabayashi et al. ${ }^{13)}$ with some modifications. From among the components in raw coffee beans, $11.4 \mathrm{mg}$ of sucrose, $10.0 \mathrm{mg}$ of chlorogenic acid, $3.0 \mathrm{mg}$ of glycine, $2.1 \mathrm{mg}$ of caffeine and $4.6 \mathrm{mg}$ of caffeic acid were put into small test tubes, in the form of single ones or combinations of them, and $1.5 \mathrm{ml}$ of McIlvain buffer ( $\mathrm{pH} \mathrm{5.5)}$ was added to each of the tubes. After $750 \mathrm{mg}$ of celite had been added in each solution, these were heated at $190^{\circ} \mathrm{C}$ for $30 \mathrm{~min}$. This was followed by the addition of $3.0 \mathrm{ml}$ of water, heating in a boiling water bath for $1 \mathrm{~min}$, cooling and centrifuging $(10,000 \mathrm{rpm} \times 10 \mathrm{~min})$. After this treatment, the supernatants were used for the mutagenicity and color intensity assays.

\section{RESULTS AND DISCUSSION}

\section{Inhibitory effects on mutagenicity by coffee extracts}

Table I shows the effects of coffee extracts
TABle I. InHibition of Mutagenicity by Coffee Extracts with Three Degrees of Roasting

One gram of coffee powder was soaked in $100 \mathrm{ml}$ of boiling water and filtered. The color intensity was measured with 6-fold diluted samples. Inhibitory activity was assayed with $0.1 \mathrm{ml}$ of $S$. typhimurium TA 98 cells. The number of $\mathrm{His}^{+}$revertants without the samples was 8,000 , and the spontaneous revertants were subtracted. The other experimental conditions are described in the text.

\begin{tabular}{lccc}
\hline & $\begin{array}{c}\text { Color } \\
\text { intensity } \\
\left(\mathrm{OD}_{400}\right)\end{array}$ & $\begin{array}{c}\text { Revertants/ } \\
\text { plate }\end{array}$ & $\begin{array}{c}\text { Inhibition } \\
(\%)\end{array}$ \\
\hline American & 2.20 & 260 & 96.8 \\
Medium & 2.63 & 94 & 98.8 \\
Italian & 2.81 & 93 & 98.8 \\
\hline
\end{tabular}

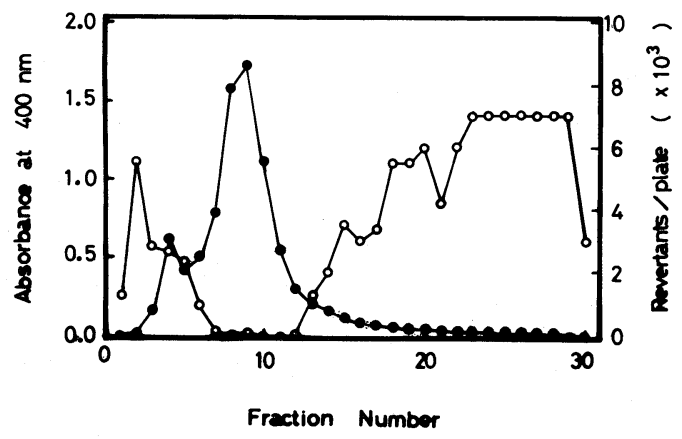

FIG. 1. Chromatography and Inhibitory Effect of the American Coffee Extract by Sephadex G-50.

One $\mathrm{ml}$ of coffee extract whose roasted degree was American (low) was applied to a Sephadex G-50 column $(1.0 \times 25 \mathrm{~cm})$. After fractionation, the color intensity and inhibitory effect on mutagenicity were determined. Inhibitory activity was assayed with $0.08 \mathrm{ml}$ of each fraction, $0.034 \mu \mathrm{g}$ of Trp-p-2 and $0.1 \mathrm{ml}$ of $S$. typhimurium TA 98 cells. The number of spontaneous revertants was subtracted.

Symbols: color intensity; $\bigcirc$, inhibitory activity.

on mutagenicity, in which the coffee beans were roasted to three different levels.

The numbers of $\mathrm{His}^{+}$revertant colonies with Trp-p-2 was apparently reduced when the coffee extract was added. Among the three coffee samples, the Italian (high roasting level) showed the highest inhibitory effect, the medium roast the second, and the American the least. This order corresponded to the degree of darkness in color of the three coffee samples.

Methylglyoxal, which has been reported to 
be contained in coffee extracts and to show mutagenicity, ${ }^{8,9)}$ was confirmed to have no inhibitory effect on the mutagenicity of these mutagens.

These results suggested that there must be some correlation between the brown pigments in the coffee extract and the inhibitory activity towards the mutagenicity of Trp-p-2.

To isolate the components showing inhibition towards the mutagenicity, one coffee extract (American) was fractionated by Sephadex G-50 column chromatography. Figure 1 shows the elution patterns of color pigments and the inhibitory activity towards mutagenicity.

The color pigments in the coffee extracts were separated into two peaks. In this figure, fraction nos. 7 $\sim 12$ were found to show high inhibitory activity towards the mutagenicity of Trp-p-2. These fractions coincided with the second peak in the elution pattern of the color pigments.

Two other coffee extracts (medium and Italian) also showed similar patterns concerning both the color pigments and the inhibitory activity towards mutagenicity (data not shown). All levels of brown pigments, especially components in the second peak, seemed to increase in proportion to the roasting.

These results indicate that a factor in the brown pigments in the second peak had the inhibitory activity towards the mutagenicity of Trp-p-2.

\section{Effects on mutagenicity of roasted products of the compounds in raw coffee beans}

To clarify the process involved in the inhibitory effect of the coffee extract against Trp-p-2, we roasted some components in raw coffee beans using the method of Nakabayashi et al. $^{13)}$

As shown in Table II, all of the samples containing chlorogenic acid and sucrose, which were very dark, showed a markedly high degree of inhibitory activity towards mutagenicity.

These results indicate that there is a close relationship between the inhibitory activity
Table II. EFfects on Mutagenicity of Roasted Products of the Components In RAW COFFEe BEANS

Color intensity was measured with 8-fold diluted samples. Inhibitory activity was assayed with $0.05 \mathrm{ml}$ of each sample, $0.17 \mu \mathrm{g}$ of Trp-p-2 and $0.1 \mathrm{ml}$ of $S$. typhimurium TA 98 cells. The number of $\mathrm{His}^{+}$revertant colonies without samples was 10,000 , and the spontaneous revertants were subtracted.

\begin{tabular}{lrrr}
\hline \multicolumn{1}{c}{ Sample } & $\begin{array}{c}\text { Color } \\
\text { intensity } \\
\left(\text { OD }_{400}\right)\end{array}$ & $\begin{array}{c}\text { Revertants } \\
\text { /plate }\end{array}$ & $\begin{array}{c}\text { Inhibition } \\
(\%)\end{array}$ \\
\hline Suc $^{a}$ & 0.77 & 5,000 & 50 \\
ChA $^{b}$ & 0.19 & 10,000 & 0 \\
Gly $^{c}$ & 0.015 & 10,000 & 0 \\
Cf $^{d}$ & 0.015 & 10,000 & 0 \\
CfA $^{e}$ & 0.31 & 136 & 99 \\
Suc + ChA & 1.84 & 116 & 99 \\
Suc + Gly & 1.44 & 2,000 & 80 \\
Suc + Cf & 0.48 & 6,000 & 40 \\
Suc + CfA & 0.90 & 418 & 96 \\
ChA + Gly & 0.53 & 7,000 & 30 \\
ChA + Cf & 0.42 & 7,000 & 30 \\
ChA + CfA & 0.49 & 83 & 99 \\
Gly + Cf & 0.04 & 10,000 & 0 \\
Gly + CfA & 0.34 & 477 & 95 \\
Cf + CfA & 0.10 & 2,500 & 75 \\
Suc + ChA + Gly & 1.97 & 264 & 97 \\
Suc + ChA + Gly & 2.37 & 131 & 99 \\
+ Cf & & & \\
Suc + ChA + Gly & 2.21 & 69 & 99 \\
+ CfA & & & \\
Suc + ChA + Gly & 2.50 & 14 & 99 \\
$\quad+$ Cf + CfA & & & \\
\hline
\end{tabular}

${ }^{a}$ Sucrose. ${ }^{b}$ Chlorogenic acid.

c Glycine. ${ }^{d}$ Caffeine. ${ }^{e}$ Caffeic acid.

and the roasting products of the mixture of chlorogenic acid and sucrose.

We also found that all of the samples containing caffeic acid, which were light brown in color, also showed high inhibitory activity towards mutagenicity.

Kato et al. ${ }^{14)}$ have reported that glucoseglycine model melanoidines showed desmutagenic activity towards the mutagenicity of Trpp-1,2, Glu-p-1,2 and 2-amino-3-methylimidazo[4,5-f]quinoline (IQ). In our experiments, too, the melanoidines from sucroseglycine also showed inhibitory activity towards mutagenicity, but a much higher inhibitory activity was observed in the combinations 
Table III. Effects of Coffee Extracts on the Mutagenicity of Various Mutagens

Cells of S. typhimurium TA 98 or TA 100 were treated at $37^{\circ} \mathrm{C}$ for 60 min with $0.1 \mathrm{ml}$ of mutagens (with or without $0.25 \mathrm{ml}$ of the S-9 mix) and $0.02,0.05$ or $0.1 \mathrm{ml}$ of $1 \%$ coffee extract, and then poured onto a histidinedeficient agar medium. The plates were incubated at $37^{\circ} \mathrm{C}$ for $48 \mathrm{hr}$, before the $\mathrm{His}^{+}$-induced revertant colonies were counted. The test strains used were $S$. typhimurium TA 98 for the assay of Trp-p-2, AAF, Glu-p-1 and IQ, and TA 100 for that of all the other mutagens. The concentrations of the mutagens per plate were: for Trp-p-2, $0.1 \mu \mathrm{g} ; \mathrm{AAF}, 10 \mu \mathrm{g} ; \mathrm{B}(\mathrm{a}) \mathrm{P}, 5 \mu \mathrm{g} ; 4 \mathrm{NQO}, 5 \mu \mathrm{g} ; \mathrm{AF}-2,0.1 \mu \mathrm{g} ; \beta$-propiolactone (BPL), $40 \mu \mathrm{g} ;$ glycidol, $500 \mu \mathrm{g}$; propylene oxide, $350 \mu \mathrm{g}$; acrolein, $10 \mu \mathrm{g}$; linolenic peroxide, $100 \mu \mathrm{g}$; methylglyoxal, $20 \mu \mathrm{g}$; DL-glyceraldehyde, $100 \mu \mathrm{g}$; dihydroxyacetone, $150 \mu \mathrm{g}$.

(a) Mutagens which showed their mutagenicity by metabolic activation with S-9 mix.

\begin{tabular}{|c|c|c|c|c|}
\hline & \multicolumn{4}{|c|}{ Revertant colonies/plate } \\
\hline & \multirow{2}{*}{ Control } & \multicolumn{3}{|c|}{ Coffee extract $(1 \%)$} \\
\hline & & $0.02 \mathrm{ml}$ & $0.05 \mathrm{ml}$ & $0.1 \mathrm{ml}$ \\
\hline Trp-p-2 & $\begin{array}{c}5,526 \\
(100.0)\end{array}$ & $\begin{array}{l}1,340 \\
(24.2)\end{array}$ & $\begin{array}{c}374 \\
(6.8)\end{array}$ & $\begin{array}{l}37 \\
(0)\end{array}$ \\
\hline Glu-p-1 & $\begin{array}{c}8,650 \\
(100.0)\end{array}$ & $\begin{array}{l}1,855 \\
(21.4)\end{array}$ & $\begin{array}{c}482 \\
(5.6)\end{array}$ & $\begin{array}{c}43 \\
(0)\end{array}$ \\
\hline AAF & $\begin{array}{c}3,616 \\
(100.0)\end{array}$ & $\begin{array}{l}1,272 \\
(35.2)\end{array}$ & $\begin{array}{c}563 \\
(15.7)\end{array}$ & $\begin{array}{l}53 \\
(0)\end{array}$ \\
\hline $\mathrm{B}(\mathrm{a}) \mathrm{P}$ & $\begin{array}{r}575 \\
(100.0)\end{array}$ & $\begin{array}{r}325 \\
(56.5)\end{array}$ & $\begin{array}{c}182 \\
(31.7)\end{array}$ & $\begin{array}{c}95 \\
(16.5)\end{array}$ \\
\hline IQ & $\begin{array}{c}3,870 \\
(100.0)\end{array}$ & $\begin{array}{r}974 \\
(25.2)\end{array}$ & $\begin{array}{c}275 \\
(7.1)\end{array}$ & $\begin{array}{c}86 \\
(2.2)\end{array}$ \\
\hline
\end{tabular}

( ): $\%$.

(b) Mutagens which showed their mutagenicity without metabolic activation.

\begin{tabular}{|c|c|c|c|c|}
\hline & \multicolumn{4}{|c|}{ Revertant colonies/plate } \\
\hline & \multirow{2}{*}{ Control } & \multicolumn{3}{|c|}{ Coffee extract $(1 \%)$} \\
\hline & & $0.02 \mathrm{ml}$ & $0.05 \mathrm{ml}$ & $0.1 \mathrm{ml}$ \\
\hline \multirow[t]{2}{*}{ AF-2 } & 955 & 735 & 468 & 245 \\
\hline & $(100.0)$ & $(77.0)$ & $(49.0)$ & $(25.7)$ \\
\hline \multirow[t]{2}{*}{ 4NQO } & 4,800 & 3,000 & 1,500 & 700 \\
\hline & $(100.0)$ & $(62.5)$ & $(31.3)$ & ( 14.6$)$ \\
\hline \multirow[t]{2}{*}{ BPL } & 1,270 & 1,350 & 1,570 & 1,890 \\
\hline & $(100.0)$ & $(106.3)$ & $(123.7)$ & $(148.8)$ \\
\hline \multirow[t]{2}{*}{ Glycidol } & 1,150 & 1,285 & 1,370 & 1,570 \\
\hline & $(100.0)$ & $(111.7)$ & $(119.1)$ & $(136.5)$ \\
\hline \multirow[t]{2}{*}{ Propylene oxide } & 627 & 520 & 746 & 935 \\
\hline & $(100.0)$ & ( 82.9) & $(119.0)$ & $(149.1)$ \\
\hline \multirow[t]{2}{*}{ Acrolein } & 595 & 583 & 603 & 695 \\
\hline & $(100.0)$ & $(98.0)$ & $(101.3)$ & $(116.8)$ \\
\hline Autoxidized & 435 & 550 & 730 & 983 \\
\hline linolenic acid & $(100.0)$ & $(126.4)$ & $(167.8)$ & $(226.0)$ \\
\hline \multirow[t]{2}{*}{ Methylglyoxal } & 1,850 & 2,250 & 3,670 & 4,370 \\
\hline & $(100.0)$ & (121.6) & (198.4) & $(236.2)$ \\
\hline \multirow[t]{2}{*}{ DL-Glyceraldehyde } & 557 & 650 & 870 & 985 \\
\hline & $(100.0)$ & $(116.7)$ & $(156.2)$ & $(176.8)$ \\
\hline \multirow[t]{2}{*}{ Dihydroxyacetone } & 663 & 710 & 920 & 1,150 \\
\hline & $(100.0)$ & $(107.1)$ & $(138.8)$ & $(173.5)$ \\
\hline
\end{tabular}


of sucrose-chlorogenic acid or sucrose-caffeic acid.

\section{Effects of coffee extracts on the S-9 activating reaction of mutagens}

Table III(a) shows the effects of coffee extracts on the mutagenicity of various mutagens which showed their mutagenicities by metabolic activation with S-9 mix.

In this table, the mutagenicity of all these mutagens were markedly inhibited by coffee extracts. Table III(b) shows the effects of coffee extracts on the mutagenicity of various mutagens which showed their mutagenicities without metabolic activation. Contrary to the mutagens in Table III(a), most of these in Table III(b), with some exceptions, were not affected by coffee extracts, and the mutagenicity of some were actually stimulated by coffee extracts.

These results suggest that coffee extracts affected the reaction between the mutagens and S-9 mix, and it is probable that coffee extracts might have inhibited the function of certain enzymes in S-9 by which the mutagens in Table III(a) were activated.

To ascertain this assumption, experiments were carried out in which the coffee extracts were added before or after metabolic activation of the mutagens by S-9 mix, and followed by an assay of their mutagenicity.

Figure 2 shows the reductive effect of coffee extracts added at the indicated periods during the process of activation of Trp-p-2, B(a)P and AAF by S- 9 mix.

In this figure, the maximum effect was observed when the coffee extracts were added prior to the process of activation. When the coffee extracts were added at a later period in the process, less effect was observed. When the coffee extracts were added after $60 \mathrm{~min}$ of the process, no effect on a decrease of mutagenicity was observed. From these results, it was confirmed that the main effect of coffee extracts may be the inhibitory action on S-9 activating reactions with the mutagens.

It has not been clarified why the mutagenicity of 2-(2-furyl)-3-(5-nitro-2-furyl)acryl-

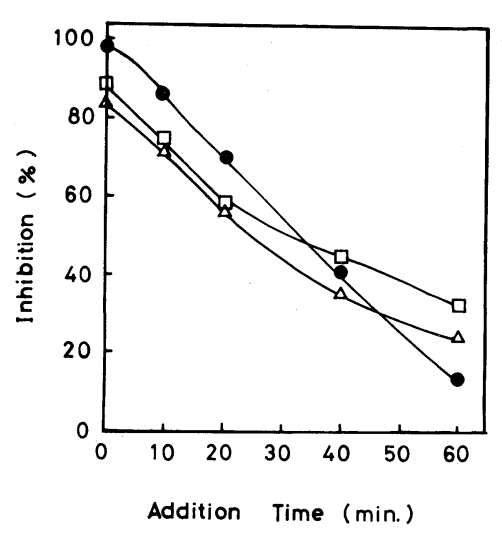

FIG. 2. Change to the Inhibition of Mutagenicity by the Addition Time of the Coffee Extract.

A reaction mixture containing a test mutagen, cells of the test strain and S-9 mix was incubated at $37^{\circ} \mathrm{C}$. At the regular intervals indicated, coffee extract was added to the mixture and incubation was continued at $37^{\circ} \mathrm{C}$ for $20 \mathrm{~min}$. After these treatments, the mutagenicity was assayed by the standard method. The test strain used was $S$. typhimurium TA 98 for the assay of Trp-p-2 and AAF, and TA 100 for $\mathrm{B}(\mathrm{a}) \mathrm{P}$. The concentration of the mutagens per plate was: for Trp-p-2, $0.1 \mu \mathrm{g}$; AAF, $10 \mu \mathrm{g}$ and B(a)P, $5 \mu \mathrm{g}$. The concentration of the coffee extract was $1 \%$ aq. solution and $0.1 \mathrm{ml}$ was used per plate. The other experimental conditions are described in the text.

Symbols: $\bigcirc$, Trp-p-2; $\square, \mathrm{B}(\mathrm{a}) \mathrm{P} ; \triangle$, AAF.

amide (AF-2) and 4-nitroquinoline-1-oxide (4NQO), which showed mutagenicity without metabolic activation, were also inhibited with the coffee extracts. The inhibition mechanism on these mutagens might be different from that on the mutagens in Table III (a).

As already mentioned, a high correlation was observed between the inhibitory activity on mutagenicity and the color pigment in the coffee extracts. The pigments in coffee extracts have been reported in detail by Nakabayashi. ${ }^{10,13)}$ According to his reports, the coffee pigments were separated into three peaks with Sephadex G-25 column chromatography. In our experiments, however, the coffee pigments of all these tested were separated into only two peaks with Sephadex G-25 or G-50 column chromatography. Although the reason of this difference is not clear, our first peak, dark brown, seems to have been similar to 
peak $\mathrm{A}$ in Nakabayashi's report, ${ }^{13)}$ and our second peak, reddish brown, could be his peak $\mathrm{B}$ and $\mathrm{C}$.

All of the mutagens used in this study are known to exist in food or the environment, and their carcinogenicity has been proved with experimental animals. It is worth noting that coffee has some mutagens, ${ }^{8,9}$ however, it is also interesting that, as the present data suggests, coffee also contains some anti-mutagens.

\section{REFERENCES}

1) T. Sugimura, T. Kawachi, M. Nagao, T. Yahagi, Y. Seino, T. Okamoto, K. Sudo, T. Kosuge, K. Tsuji, K. Wakabayashi, Y. Iitaka and A. Itai, Proc. Japan Acad., 53, 58 (1977).

2) T. Matsumoto, D. Yoshida, S. Mizusaki and $\mathrm{H}$. Okamoto, Mutation Res., 48, 279 (1977).

3) T. Kada, K. Morita and T. Inoue, Mutation Res., 53, 351 (1978).
4) S. Arimoto, Y. Ohara, T. Namba, T. Negishi and H. Hayatsu, Biochem. Biophys. Res. Commun., 92, 662 (1980).

5) T. Yamaguchi, Agric. Biol. Chem., 46, 2373 (1982).

6) H. Hayatsu, S. Arimoto, K. Togawa and M. Makita, Mutation Res., 81, 287 (1981).

7) S. R. Sirianni, H. H. Chen and C. C. Huang, Mutation Res., 90, 175 (1981).

8) M. Nagao, T. Takahashi, H. Yamanaka and T. Sugimura, Mutation Res., 68, 101 (1979).

9) H. Kasai, K. Kumeo, Z. Yamaizumi, S. Nishimura M. Nagao, Y. Fujita, T. Sugimura, H. Nukaya and T. Kosuge, Gann, 73, 681 (1982).

10) T. Nakabayashi, Nippon Shokuhin Kogyo Gakkaishi, 22, 507 (1975).

11) B. N. Ames, J. McCánn and E. Yamasaki, Mutation Res., 31, 347 (1978).

12) T. Yahagi, Tampakushitsu Kakusan Koso, 20, 1178 (1975).

13) T. Nakabayashi and C. Watanabe, Nippon Shokuhin Kogyo Gakkaishi, 24, 124 (1975)

14) H. Kato, S. B. Kim, F. Hayase and N. V. Chuyen, Agric. Biol. Chem., 49, 3093 (1985). 